19 Revue d'histoire du XIXe siècle

Société d'histoire de la révolution de 1848 et des

révolutions du XIXe siècle

$22 \mid 2001$

Autour de Décembre 1851

\title{
À nos lecteurs
}

Réédition de l'article paru dans 1848 - Revue des révolutions contemporaines, n 189, décembre 1951

\section{La Rédaction}

\section{OpenEdition}

\section{Journals}

Édition électronique

URL : http://journals.openedition.org/rh19/254

DOI : $10.4000 /$ rh 19.254

ISSN : $1777-5329$

\section{Éditeur}

La Société de 1848

\section{Édition imprimée}

Date de publication : 1 juin 2001

ISSN : 1265-1354

Référence électronique

La Rédaction, «À nos lecteurs », Revue d'histoire du XIXe siècle [En ligne], 22 | 2001, mis en ligne le 04 septembre 2008, consulté le 01 mai 2019. URL : http://journals.openedition.org/rh19/254 ; DOI 10.4000/rh19.254

Ce document a été généré automatiquement le 1 mai 2019.

Tous droits réservés 


\title{
À nos lecteurs
}

\begin{abstract}
Réédition de l'article paru dans 1848 - Revue des révolutions contemporaines, n 189, décembre 1951
\end{abstract}

\section{La Rédaction}

Le présent numéro de notre revue est le dernier d'une année, le dernier d'une série. Il paraît au moment où une situation difficile, sur la gravité de laquelle nous insistions lors de notre assemblée générale, arrive à complète maturité et menace notre Société d'une catastrophe.

Nous devons donc à tous nos sociétaires, un bilan de cette situation, une explication de cette catastrophe.

$* * *$

Comme tous les groupements de spécialistes, la Société d'Histoire de la Révolution de 1848 ne pouvait compter et ne compte effectivement qu'un nombre restreint de participants. Très exactement, selon les indications de M. Pérotin, notre dévoué trésorier, 105 sociétaires (pour la plupart universitaires) ont réglé leur cotisation pour l'année $1951 ; 108$ abonnés (pour la majeure partie Universités, Bibliothèques, Centres de documentation d'appartenances très diverses) ont fait de même. Ce qui assurait à la Société, pour cette même année, des recettes de l'ordre de 77580 francs.

Chiffres très insuffisants, au regard de nos dépenses : sans tenir compte des frais de bureau, de correspondance, de téléphone, que la bonne volonté de chacun de nous permet de réduire au strict minimum, il faut songer que le premier numéro de 1951 a coûté 80636 francs (plus que l'ensemble des recettes annuelles) et que le second représente compte tenu de l'augmentation du papier au minimum 100000 francs. Si nous avons pu durer, dans ce déséquilibre, c'est grâce à la subvention de 200000 francs accordée par le Comité National du Centenaire de la Révolution de 1848, et obtenue surtout grâce aux bons offices de M. Charles_H. Pouthas auquel nous sommés heureux de témoigner, une fois de plus, notre gratitude.

Mais il n'est réserve qui ne s'épuise et cette constatation nous amena à nous adresser en mai dernier, une demande de subvention au Comité National de la Recherche Scientifique. Le 2 juillet, nous recevions une réponse qui était un refus formulé en des termes d'une concision que l'on peut juger excessive : " J'ai l'honneur de vous informer 
que la Commission compétente à laquelle j'ai soumis cette demande n'a pas cru devoir la retenir "

***

Aucune explication complémentaire ne nous a été, ni alors, ni depuis fournie et la

" Commission compétente " a gardé le secret de sa décision.

Nous serions heureux, pourtant, de connaître les raisons d'une telle décision

l'insuffisance des crédits ne peut être évoquée, da nombreuses revues d'histoire

bénéficiant de subventions du CNRS, sans que l'on puisse affirmer, croyons_nous, qu'elles présentent un intérêt plus grand ou une tenue scientifique plus haute que la nôtre.

Et certes, ce que nous avons publié est d'inégale qualité et l'intérêt n'en est pas toujours soutenu. Qu'on veuille bien, néanmoins, parcourir la Table des Matières qui paraît dans le présent fascicule, qu'on veuille bien, en toute indépendance, feuilleter nos numéros et l'on s'apercevra, si l'on conserve cette impartialité devant les faits, qui demeure la qualité essentielle d'un historien, que notre périodique offre autant de sérieux, da matière historique et de documents que les revues qui bénéficient des faveurs de " la commission compétente ".

***

Peut_être sera_t_il possible d'en appeler, dans un proche avenir, du CNRS sans doute insuffisamment informé, à un CNRS mieux informé. Mais, sans préjuger du résultat que pourront obtenir d'ultérieures démarches, il faut vivre et durer. Ce qui n'est pas facile, on le reconnaîtra, avec des ressources aussi modiques que les nôtres.

Le Bureau, après avoir mûrement étudié et discuté la question, s'est arrêté aux solutions suivantes qui lui paraissent pour les temps difficiles que nous vivons les moins mauvaises, en ce sens qu'elles sauvegardent l'avenir :

Interrompre (provisoirement, nous l'espérons), la publication de notre Revue.

Tenir chaque année, trois réunions : en février, en mal, en novembre, alimentées par des communications groupées, dans la mesure du possible, autour d'un thème central, le Coup d'État de décembre 1851 devant être l'objet des communications prévues pour notre réunion de février 1952.

Publier, après chacune de ces réunions un bulletin bref mais aussi substantiel que possible. Le résumé des communications en sera la base essentielle.

Au total une activité " en veilleuse " la seule que nous puissions présentement nous permettre. Mais pour qu'elle soit possible, il faut que nos sociétaires, que nos abonnés nous demeurent fidèles, qu'ils fassent corps ; il faut qu'ils acceptent de continuer à payer des cotisations, tout en sachant par avance qu'elles ne leur donneront qu'une nourriture historique restreinte.

Nous croyons pouvoir faire fonds sur cette fidélité. Il ne s'agit pas, que l'on s'en persuade, d'une question mesquine de boutique, il ne s'agit pas que l'entêtement ou une sotte vanité soient en cause de maintenir une entreprise à l'avance condamnée. Dans l'étroit secteur où nous combattons, nous représentons la cause de l'honnêteté dans le labeur historique, la cause de l'indépendance de la pensée historique. Servies par des exécutants modestes parfois, sans doute inférieurs à leur tâche ces causes sont pourtant des fractions importantes, et même vitales, de notre patrimoine intellectuel. Elles méritent d'être défendues, et c'est pourquoi nous comptons sur vous. 